\title{
A IMPORTÂNCIA DO TRABALHO DIFERENCIADO DENTRO DA DISCIPLINA DE MATEMÁTICA NO ENSINO FUNDAMENTAL
}

\author{
Amanda Alves de Lima - UFCG ${ }^{1}$ \\ Rachel Rawennia Coelho Lima ${ }^{2}$ \\ Rosinângela Cavalcanti da Silva ${ }^{3}$
}

\begin{abstract}
RESUMO
Em virtude da indispensabilidade de mudanças no processo de ensino aprendizagem de Matemática, serão abordados quesitos sobre o tema, com o intuito que haja uma mudança na metodologia de ensino dos professores de Matemática. Deste modo, o ponto primordial deste trabalho será discutir sobre as práticas no ensino de Matemática, mostrando a importância de uma abordagem contextualizada, dinâmica e inovadora dos conteúdos, cabendo aos docentes repensar seu planejamento, tornando-o diferenciado. Para isso, o professor terá que dispor, também, de recursos didáticos, e identificar o âmbito em que o discente e a escola se inserem. Dessa maneira, proporcionará um melhor desenvolvimento do educando. Para a realização desse estudo foi elaborado um questionário e aplicado a discentes do Curso de Licenciatura em Matemática dessa instituição, que já tiveram experiência, vivendo de perto essa realidade, no contexto escolar, e que cursaram ou estão cursando a disciplina de Prática de Ensino de Matemática no Ensino Fundamental. Foram levantadas questões acerca da importância das ferramentas e atividades diferenciadas que podem ser utilizadas nas aulas de Matemática, visando que, aulas bem planejadas, com recursos adequados, facilitam a aprendizagem dos educandos. Constatamos que, em sua totalidade, os discentes que participaram da pesquisa, reconhecem quão importantes são o uso e a exploração desses recursos em sala de aula.A partir dos resultados obtidos dos questionários e do embasamento teórico acerca do tema em discussão, poderá ser evidenciada a relevância dos métodos diferenciados para o ensino inovador na disciplina de Matemática, dando-lhe mais característica e singularidade, aspectos próprios dessa disciplina. Em consonância com este pensamento, estão as discussões na disciplina da grade curricular do curso de Matemática, Prática de Ensino de Matemática no Ensino Fundamental, cuja é a base para uma formação aperfeiçoada dos discentes no quesito de atuação profissional.
\end{abstract}

Palavras Chaves: Ensino Diferenciado. Planejamento. Educando.

\section{THE IMPORTANCE OF DIFFERENTIATED WORK INSIDE THE DISCIPLINE OF MATHEMATICS IN THE ELEMENTARY EDUCATION}

\author{
ABSTRACT \\ Given the indispensability of changes in the teaching learning Mathematics, \\ questions will be addressed on the subject, in order that there is a change in teaching \\ methodology of Mathematics teachers. Thus, the primary point of this paper will \\ discuss the practices in the teaching of Mathematics, showing the importance of a

\footnotetext{
${ }^{1}$ Universidade Federal de Campina Grande. E-mail: amandalimasjp@ gmail.com

${ }^{2}$ Universidade Federal de Campina Grande. E-mail: rachelmatematica2013@gmail.com

${ }^{3}$ Professora na Universidade Federal de Campina Grande. E-mail: rosinangela_sip@hotmail.com
} 
contextual approach, dynamic and innovative content, leaving teachers to rethink its planning, making it different. For this, the teacher will have to have, too, teaching resources, and identify the extent to which the student and the school is located. In this way, provide a better development of the student.To perform this study a questionnaire was developed and applied to students of Mathematics in Bachelor of that institution, who have had experience, close to living this reality in the school context, and who attended or are attending the Teaching Practice discipline Mathematics in Elementary Education. Questions were raised about the importance of different tools and activities that can be used in math classes, aiming, well planned lessons, with adequate resources, facilitate students' learning. We note that, in its entirety, the students in the survey recognize how important the use and exploitation of these classroom resources. From the results obtained from questionnaires and theoretical background on the subject under discussion, it may be shown the relevance of different methods for innovative teaching in Mathematics, giving it more character and uniqueness, specific aspects of the discipline. In line with this thinking, are the discussions on the course curriculum of the course of Mathematics, Mathematics Teaching Practice in Elementary Education, which is the basis for improved training of students in the category of professional performance.

Keywords: Differentiated education. Planning. Educating.

\section{INTRODUÇÃO}

O presente trabalho tem como objetivos apresentar uma breve análise acerca da forma de como é trabalhado o ensino de Matemática nas escolas, e abordar a importância da utilização de técnicas diferenciadas para um inovar em sala de aula.

Atualmente, a Matemática está presente em tudo ao nosso redor, entretanto os alunos estão habituados a vê-la de forma descontextualizada, para eles, a Matemática é uma disciplina muito complicada e constrangedora. O ensino de Matemática vem passando por diversos fatores negativos no decorrer do tempo, entre eles, podemos citar, a falta de planejamento, a paciência limitada que a maioria dos professores tem com o aluno, a falta de empenho em estudar novas tendências e metodologias diferenciadas, comodidade apenas no tradicionalismo, falta de recursos tecnológicos. Esses e outros quesitos, sendo colocados em prática, capacitam um profissional qualificado na realização do seu trabalho.

RPI Revista de Pesquisa Interdisciplinar, Cajazeiras, v. 1, Ed. Especial, 564 - 572, set/dez. de 2016. 
A maneira como o professor repassa o conteúdo influencia bastante no desenvolvimento do aluno, dessa forma um bom profissional é aquele que dispõe de todo o seu trabalho para ampliar os caminhos necessários para facilitar a aprendizagem do aluno. O professor não deve se prender somente ao tradicionalismo, cabe a ele desenvolver formas e métodos para ampliar a sua base metodológica, no qual, centre suas atenções voltadas ao bem estar social do aluno. As novas tecnologias seriam um ótimo suporte para dinamizar e facilitar a aprendizagem dos alunos, pois ela está próxima a realidade dos mesmos.

Aprender é um ato de conhecimento da realidade concreta, isto é, da situação real vivida pelo educando, e só tem sentido se resulta de uma aproximação crítica dessa realidade. Portanto o conhecimento que o educando transfere representa uma resposta à situação de opressão a que se chega pelo processo de compreensão, reflexão e crítica. (LIBÂNEO, 1991, P.54).

Para se abordar o conteúdo em sala de aula, o professor pode adotar maneiras diferenciadas de apresentá-lo aos alunos. Uma dessas maneiras é o uso da contextualização, que contribui grandemente para uma maior significação do conteúdo. Em consonância com esse pensamento, D’Ambrósio afirma que:

Contextualizar a Matemática é essencial para todos. Afinal, como deixar de relacionar os Elementos de Euclides com o panorama cultural da Grécia Antiga? Ou a adoção da numeração indo-arábica na Europa como florescimento do mercantilismo nos séculos XIV e XV? E não se pode entender Newton descontextualizado. (...) Alguns dirão que a contextualização não é importante, que o importante é reconhecer a Matemática como a manifestação mais nobre do pensamento e da inteligência humana... e assim justificam sua importância nos currículos (D'AMBROSIO, 2001).

Nessa mesma linha de pensamento, Sadovsky observa que (2007,p.8):

[...] a Matemática, não só no Brasil, é apresentada sem vínculos com os problemas que fazem sentido na vida das crianças e dos adolescentes. Os aspectos mais interessantes da disciplina, como resolver problemas, discutir idéias, checar informações e

RPI Revista de Pesquisa Interdisciplinar, Cajazeiras, v. 1, Ed. Especial, 564 - 572, set/dez. de 2016. 
ser desafiado, são pouco explorados na escola. O ensino se resume a regras mecânicas que ninguém sabe, nem o professor, para que servem.

É notório que, em suas aulas, o professor de Matemática se restringe a aplicar regras, fórmulas e modelos, desligando-se totalmente do contexto real vivenciado pelo aluno, o que contribui para o não aprendizado significativo deste.

Diante dessa realidade, foi intencionado realizar esta atividade de pesquisa, desenvolvida na monitoria da disciplina de Prática de Ensino de Matemática no Ensino Fundamental, com os discentes dessa instituição, para saber a opinião destes diante da prática do professor de Matemática, tendo o intuito de descobrir e incentivar nos futuros professores uma prática eficaz, que possibilite um crescimento não apenas para o aluno, mas também para o profissional da educação.

O modo como se é trabalhado o ensino de Matemática atualmente, voltando-se apenas para uma perspectiva tradicional, na qual prevalece a reprodução e a mecanização, evidencia a falta de planejamento e empenho do professor. Com isso, a sala de aula vai acabar perdendo espaço para toda agitação que pode ser encontrada fora dos muros escolares. Por isso, é fundamental que o professor inove sua maneira de ensinar, tirando aquele pressuposto de que os únicos aliados do professor são apenas o quadro e o giz. É nessa linha de pensamento que Veiga (1996) afirma:

O trabalho docente alienado só pode gerar um produto discente alienado; se isso não acontece é porque o aluno conseguiu, por outros caminhos, criticar a prática de seu professor. É por esse motivo que afirmamos que o professor precisa saber como se constitui o conhecimento. Caso contrário, poderá não só tornar inócuo o processo de aprendizagem, como até obstruir o processo de desenvolvimento que o fundamenta. (VEIGA, 1996: p. 68-69).

A disciplina de Matemática exige muito empenho, planejamento, disposição, e cabe aos docentes, buscar alternativas adequadas para tornar o ato de ensino aprendizagem algo prazeroso e satisfatório, contribuindo assim, para a formação de alunos críticos e transformadores do meio em que se vive. E é com esse objetivo que foram criadas ferramentas para complementar essa tarefa de educar e mediar o 
conhecimento. Tais ferramentas virão como auxílio para o professor, que deverá desenvolver habilidades e competências no aluno, que por sua vez, terá um ensino prazeroso e propício a diversas descobertas.

A metodologia utilizada foi uma entrevista realizada com alunos que estavam cursando e que já cursaram a disciplina Prática de Ensino de Matemática no Ensino Fundamental, enriquecida com pesquisas bibliográficas.

O que foi percebido durante a realização dos questionários, com os alunos que já cursaram e os que estão cursando a disciplina Prática de Ensino de Matemática no Ensino Fundamental, é que estes já adquiriram um pensamento inovador e se mostram propagadores do novo modelo dinâmico, que não se restringe a uma única forma de ensinar, adotando métodos diferenciados de se ensinar Matemática em sala de aula, fugindo do convencional e incorporando novos ideais.

Sendo assim, foi abordada a importância do trabalho diferenciado dentro da disciplina de Matemática no Ensino Fundamental, enfatizando como o uso de ferramentas dá significado ao estudo dos conteúdos de Matemática em sala de aula, incentivando a participação e empenho do aluno.

\section{Desenvolvimento}

Diante de uma geração informatizada, portadora de fontes de conhecimentos inesgotáveis, o espaço de uma sala de aula não é suficiente para abranger toda essa gama de informação. É nesse contexto, que o professor deve transformar o ambiente de sala de aula em um espaço repleto de inovações e bombardeado de fluxos de saberes. Para o professor de Matemática, essa atividade se torna ainda mais intensa, tendo em vista que, os mitos e paradigmas acerca desta, constroem barreiras e obstáculos para uma aceitação significativa por parte dos alunos.

Nessa perspectiva, levantamos questões embasadas no trabalho desenvolvido em sala de aula, enfatizando a aplicação de atividades diferenciadas, que serão o alicerce para a elaboração e execução desse trabalho. Tal uso de atividades diferenciadas é bastante discutido na disciplina de Prática de Ensino de Matemática no Ensino 
Fundamental, com a qual são desenvolvidos e aperfeiçoados ideais e práticas do docente em formação.

Buscando opiniões diversificadas de alunos que já tiveram contato com a sala de aula, e também daqueles, que foram auxiliados por essa monitoria no planejamento e elaboração de aulas diferenciadas para o cumprimento das simulações de aula propostas na disciplina citada, sendo estes portadores de um posicionamento e requisitos para determinar a postura do professor ideal, é que foi elaborado um questionário que será a base para o desenvolvimento deste trabalho.

No questionário, os alunos poderiam apontar a importância do uso de novos métodos, enfatizando o enriquecimento que estes proporcionam para o desenvolvimento de aulas mais estimulantes, assim como, sua insatisfação em relação a esse método de ensino, falando abertamente da necessidade ou não de algo novo, diferenciado, inovador, tecnológico e dinâmico para a sala de aula.

Foram 37 alunos entrevistados, os quais, em sua totalidade, se manifestaram de forma positiva em relação à adoção de novas metodologias, evidenciando como é gratificante elaborar uma aula com ideais divergentes dos preexistentes de fundo tradicionalista e desconectado. Nas questões abertas, foi citado diversas vezes que os métodos tradicionais não funcionam mais, embora ainda sejam bastante utilizados em nossas escolas. Além desse apontamento, explicitaram que o uso do método diferenciado propicia ao aluno notar conexões e entrelaços entre o mundo matemático e o contexto real, embora essa ciência tenha surgido das necessidades do nosso real, construindo saberes e simplificações para os diversos problemas que surgiram ao longo da história da humanidade. Ainda foi destacado um nível de fixação maior dos conteúdos utilizando essa forma de ensino, além do impulso de participação dos alunos em aulas mais interativas, e a necessidade de mais dedicação, empenho e planejamento para sua execução.

São diversas as ferramentas para o desenvolvimento de uma prática efetiva em sala de aula: jogos, dinâmicas, situações problemas, objetos concretos, História da Matemática, recursos tecnológicos como GeoGebra e Excel. Enfim, existem muitas ferramentas, que foram criadas e vêm sendo lapidadas a cada dia pelos professores, mestres que também revolucionam, criando novos recursos, tornando infinitas as maneiras de abordar diversos conteúdos e promovendo o aprimoramento dos modelos 
de ensino, que deixam de ser modelos prontos e acabados para se adaptar a cada realidade estudantil.

Para a coleta de dados, foi realizado um questionário, contendo 5 questões sobre a importância da disciplina de Prática de Ensino para a formação docente, com alunos que já cursaram e os que estão cursando a disciplina de Prática de Ensino de Matemática no Ensino Fundamental. Nele foram enfatizados os seguintes pontos: como os estudantes experientes e os que estão vivenciando agora, avaliam a disciplina no que se refere à sua formação docente, sendo questionado se o professor de Matemática do ensino fundamental deve dispor de ferramentas que auxiliam no processo de ensino aprendizagem; qual é a importância de atividades diferenciadas nas aulas de Matemática; a experiência adquirida através das simulações de aulas, se as mesmas são importantes para a sua formação docente, relacionando-as com as observações feitas no ensino fundamental; as atitudes que o professor deve ter para uma boa prática docente; e como a disciplina Prática de Ensino de Matemática no Ensino Fundamental pode contribuir para a formação deste. Todos os quesitos foram respondidos com tranquilidade e segurança.

\section{Considerações Finais}

Professores e formandos em licenciatura são desafiados a cada dia a criar algo novo e transformador na vida dos alunos. As ações, escolhas, métodos e formas de execução destes profissionais em sala de aula agem de forma direta sobre os educandos, que poderão ser influenciados de forma positiva ou negativa.

Para propagar um ensino realmente relevante para a classe estudantil é necessário rever as práticas, procurando incluir ou excluir destas, o que é essencial ou descartável, respectivamente. A prática sobre a prática impulsiona um repensar da própria prática de ensino. Para o melhoramento dessa tarefa existem inúmeros recursos que devem ser reconhecidos por um significativo número de professores em formação e em atuação.

Diante dos dados obtidos da pesquisa e as discussões acerca do tema, constatamos a importância de uma abordagem diferenciada do conteúdo, em especial nas aulas de Matemática. Acadêmicos ainda em formação já se familiarizam com a 
inovação no ensino, sendo capaz de distingui-la do modelo tradicional, incorporando novos métodos e novas ideologias em sua prática.

A Prática repensada, aliada com as ferramentas certas, produz frutos significativos. O professor é essencial para a execução desse trabalho, tendo o aluno como um ser crítico que já possui conhecimentos prévios e que verá nas ferramentas do seu mestre a ligação entre os seus conhecimentos preexistentes e os saberes que irá descobrir.

Os saberes oriundos de diversas fontes são indispensáveis para a formação intelectual do ser humano. Dentre eles, os saberes matemáticos constituem grande parte das descobertas existentes e são primordiais, não devendo ser transmitidos aos alunos como algo sem valor algum. Sendo assim, é essencial o trabalho diferenciado no ensino da disciplina de Matemática

\section{REFERÊNCIAS}

D’AMBROSIO, Ubiratan. Educação Matemática: da teoria à prática. Campinas, Papirus, 2001 (Coleção Perspectiva em Educação Matemática).

LIBÂNEO, José Carlos. Didática. São Paulo: Cortez, 1991.

SADOVSKY, Patrícia. Falta fundamentação didática no ensino de matemática. Revista Nova Escola, Editora Abril, São Paulo. Ed.Especial14.p.08-10.Jul.2007.

VEIGA, Ilma Passos Alencastro (org.). Projeto político-pedagógico da escola: uma construção possível. Campinas: Papitus, 1996.

RPI Revista de Pesquisa Interdisciplinar, Cajazeiras, v. 1, Ed. Especial, 564 - 572, set/dez. de 2016. 